\title{
Preventive Effects of Vitamin C on Diethylnitrosamine-induced Hepatotoxicity in Smp30 Knockout Mice
}

\author{
YOUNG-SOOK SON, H.M. ARIF ULLAH, AHMED K. ELFADL, MYUNG-JIN CHUNG, SOONG-GU GHIM, \\ YONG DEUK KIM, EUN-JOO LEE, KYUNG-KU KANG and KYU-SHIK JEONG \\ College of Veterinary Medicine and Stem Cell Therapeutic Research Institute, \\ Kyungpook National University, Daegu, Republic of Korea
}

\begin{abstract}
Vitamin C (L-ascorbic acid) is well known as a free radical scavenger that protects cells against damage from oxidative stress. Herein, we investigated the effects of vitamin $C$ against diethylnitrosamine (DEN)-induced hepatotoxicity. Male wild-type $(C 57 B L / 6)$ and senescence marker protein-30 (Smp30) knockout (KO) mice were used and divided in the following four groups: WT group $(n=15)$ : Wild-type (WT) mice fed vitamin $C$-free diet with tap water; WV group (n=14): WT mice fed vitamin $C$-free diet with water supplemented with $1.5 \mathrm{~g} / \mathrm{kg}$ vitamin $C$; KT group $(n=12)$ : Smp30 KO mice fed vitamin $C$-free diet with tap water; and $K V$ group $(n=13):$ Smp30 KO mice fed vitamin $C$-free diet with water supplemented with $1.5 \mathrm{~g} / \mathrm{kg}$ vitamin $C$. A single intraperitoneal injection of DEN $(5 \mathrm{mg} / \mathrm{kg}$ body weight) was injected in the second week during the experimental period. Mice were sacrificed after 17 weeks of treatment to investigate the effect of dietary vitamin $C$ on $D E N$-induced hepatotoxicity. The results showed that vitamin $C$ significantly increased the mean lifespan $(p<0.05)$ in the $W T, W V$ and $K V$ groups compared with the KT group. The serum concentrations of $\gamma$-glutamyl transpeptidase, alanine aminotransferase, and aspartate aminotransferase did not significantly differ among groups. The WT group exhibited significantly more acute cellular swelling accompanied by centrilobular necrosis, focal lymphocyte infiltration, and eosinophilic intracytoplasmic inclusion bodies as compared with the $W V$ and $K V$ groups, suggesting that vitamin $C$ had
\end{abstract}

This article is freely accessible online.

Correspondence to: Professor, Kyu-Shik Jeong, DVM, Ph.D., College of Veterinary Medicine, Kyungpook National University, Daegu City 41566, Republic of Korea. Tel: +82 539505975, Fax: +82 539505955, e-mail: jeongks@knu.ac.kr

Key Words: Vitamin C, diethylnitrosamine, hepatocellular carcinoma, Smp30 KO mice. a hepatoprotective effect. Dysplastic, large, and binucleated hepatocytes were also observed in the WT group, but these pathological signs were absent from the $W V$ and $K V$ groups. Our experimental evidence suggests that vitamin $C$ supplementation in Smp30 KO mice was effective for the treatment of DEN-induced hepatotoxicity.

Hepatocellular carcinoma (HCC) is the third leading cause of cancer-related death, resulting in approximately 0.7 million deaths each year, and the sixth most common malignancy worldwide (1-3). The recognized risk factors for HCC are hepatic disorder associated with steatosis, cirrhosis, viral hepatitis, alcohol, chemical agents, obesity, metabolic syndrome, and so forth (4). Despite recent advances in diagnosis and treatment, the effectiveness of therapy for HCC remains unsatisfactory, and $\mathrm{HCC}$ has a hidden development and a poor prognosis $(5,6)$. Therefore, there is an urgent requirement for novel therapeutic compounds for the treatment of patients with HCC. Many animal models of hepatocarcinogenesis have been established to examine the effects of therapeutic agents. Diethylnitrosamine (DEN) is frequently used as a hepatocarcinogenic agent in rodents (1). In our experimental model, externally visible foci were observed and measured by stereomicroscopy. It has been established that DEN induces HCC in animals with a developmental course similar to that of human HCC (7). Furthermore, DEN is an indirect alkylating agent that induces the generation of reactive oxygen species (ROS), which damage DNA through oxidation (8).

Senescence marker protein-30 (SMP30) is a calciumbinding protein, and its levels in the liver, kidney, and lung become significantly down-regulated with aging in an androgen-independent manner $(9,10)$. SMP30 plays an important role in calcium $\left(\mathrm{Ca}^{2+}\right)$ homeostasis (11). $\mathrm{Ca}^{2+}$ is one of the most universal and physiologically significant signaling molecules that especially affects cell apoptosis and cell necrosis (12). Other reports have indicated that SMP30 participates in controlling the activity of antioxidant enzymes 
Table I. Experimental schedules. All mice were intraperitoneally injected with diethylnitrosamine $(5 \mathrm{mg} / \mathrm{kg})$ at 2 weeks.

\begin{tabular}{ll}
\hline Group & Animal type and diet \\
\hline WT & Wild-type mice, vitamin C-free diet \\
WV & Wild-type mice, vitamin C-free diet + water supplemented with $1.5 \mathrm{~g} / \mathrm{kg}$ vitamin C \\
KT & Smp30 KO mice, vitamin C-free diet \\
KV & Smp30 KO mice, vitamin C-free diet + water supplemented with $1.5 \mathrm{~g} / \mathrm{kg}$ vitamin C \\
\hline
\end{tabular}

(13). SMP30 protein has an activating effect on cytoplasmic superoxide dismutase in liver and heart cells $(14,15)$. SMP30 also functions as an antioxidant protein that has a protective action against oxidative stress without influencing antioxidant enzyme expression (13). SMP30 suppresses the generation of ROS in hepatocytes (16), and decreased levels of SMP30 during aging were correlated with increased ROS generation in rat liver and kidney (17).

SMP30 is also involved in vitamin C (L-ascorbic acid) biosynthesis and catalyzes the lactonization of L-gulonic acid (9). Vitamin $C$ is well known as a free radical scavenger that protects cells against damage caused by oxidative stress (18). Oxidative stress induces a cellular redox imbalance that is present in various cancer cells but not in normal cells; the redox imbalance thus may be related to oncogenic processes (19).

To our knowledge, no studies related to HCC have been conducted using Smp30 knockout (KO) mice, that cannot synthesize vitamin $\mathrm{C}$ in vivo (20). Therefore, we designed our experiment to elucidate the physiological effect of vitamin $\mathrm{C}$ on DEN-induced hepatocarcinogenesis in Smp30 $\mathrm{KO}$ mice.

\section{Materials and Methods}

Animals and chemicals. Eight- to nine-week-old male wild-type (C57BL/6) and Smp30 KO mice weighing 24-29 g were obtained from the Pathology Laboratory, College of Veterinary Medicine, Kyungpook National University, South Korea. All the experiments were carried out based on the National Institute of Health guidelines. Mice were housed in an automatically controlled environment at $22 \pm 1^{\circ} \mathrm{C}$ with $55 \pm 5 \%$ relative humidity under a $12 \mathrm{~h}$ light/dark cycle. Vitamin C ( $\geq 98 \%$ purity) and DEN were purchased from Sigma-Aldrich Chemical Co. (St. Louis, MO, USA). All other chemicals were purchased from commercial suppliers and were of the highest grade.

Experimental procedure. Wild-type (WT) and Smp30 KO mice were divided into four different experimental groups. All the mice were intraperitoneally injected with a single dose of DEN $(5 \mathrm{mg} / \mathrm{kg}$ body weight) in the second week of the 17 -week experimental period. To elucidate the effect of vitamin $\mathrm{C}$ on the liver, the four groups were maintained for 17 weeks as follows: WT group $(n=15)$ : WT mice fed vitamin $\mathrm{C}$-free diet with tap water; WV group $(\mathrm{n}=14)$ : WT mice fed vitamin C-free diet with water supplemented with $1.5 \mathrm{~g} / \mathrm{kg}$ vitamin $\mathrm{C}$; KT group ( $\mathrm{n}=12)$ : Smp30 $\mathrm{KO}$ mice fed vitamin $\mathrm{C}$-free diet with tap water; and KV group $(\mathrm{n}=13)$ : Smp30 KO mice fed vitamin C-free diet with water supplemented with $1.5 \mathrm{~g} / \mathrm{kg}$ vitamin C (Table I). All mice were sacrificed under anesthesia using ethyl ether at 17 weeks. Blood samples were collected and liver tissues were fixed in $10 \%$ neutral buffered formalin and then stored at $-80^{\circ} \mathrm{C}$ until analysis.

Lifespan observation among experimental model organisms. The experimental mice were maintained for 17 weeks until sacrifice. The numbers of living mice in experimental groups were as follows: WT: $n=15 / 15$; WV: $n=14 / 14$; KT: $n=1 / 12$; and KV: $n=13 / 13$.

Biochemical analysis for the assessment of liver function. Blood samples were collected from the mice and centrifuged at $1200 \times g$ for $20 \mathrm{~min}$ at $4^{\circ} \mathrm{C}$ to separate the serum. The serum levels of $\gamma$ glutamyl transpeptidase (GGT), alanine aminotransferase (ALT), and aspartate aminotransferase (AST) were measured using an automated blood chemistry analyzer (7600, Hitachi, Tokyo, Japan).

Histopathological analysis. For histopathological evaluation, the liver tissues were rapidly removed, washed with cold normal saline, fixed in $10 \%$ neutral buffered formalin solution, processed routinely, dehydrated, and embedded in paraffin wax. Tissue was cut into sections of 6 - to 8 - $\mu \mathrm{m}$ thickness, deparaffinized, and hydrated. The liver sections were then stained with hematoxylin and eosin. Finally, hepatic pathological changes were observed and diagnosed under a microscope.

Statistical analysis. The results are presented as means \pm standard deviation. The data were analyzed by one-way analysis of variance followed by Dunnett's $t$-test for multiple comparisons using SPSS version 12.0 (SPSS Inc., Chicago, IL, USA). The differences were considered significant at $p$-values of less than 0.05 .

\section{Results}

Effect of vitamin $C$ on lifespan in DEN-treated mice. In the KT group (vitamin C-deficient), only one mouse remained alive throughout the experimental period. In contrast, all mice in the WT, WV, and KV groups lived until sacrifice at the end of the experimental period (Table II). The mortality of the KT group was $91.7 \%(11 / 12)$, which is significantly $(p<0.05)$ higher than that of the WT, WV, and KV groups, suggesting that vitamin $\mathrm{C}$ has a pivotal role in the aging process. This result indicates that vitamin $\mathrm{C}$ supplementation may prolong lifespan (21). 
Table II. Effect of vitamin C on mortality of diethylnitrosamine-treated mice.

\begin{tabular}{lccc} 
Group & Number of mice (n) & Number of deaths (n) & Mortality (\%) \\
\hline WT & 15 & 0 & 0 \\
WV & 14 & 0 & 0 \\
KT & 12 & 11 & 91.7 \\
KV & 13 & 0 & 0 \\
\hline
\end{tabular}

Numbers of foci of eosinophil-related necrosis in the liver periphery. In the WT and Smp30 KO mice, we observed foci $(\geq 0.5 \mathrm{~mm}$ ) in the liver periphery. Therefore, microscopic foci were dissected from 6 -to 8 - $\mu$ m-thick paraffin sections under microscopic observation. In the WT group, we observed a large number of foci in comparison to the vitamin Csupplemented WV and KV groups (data not shown). These data suggest that vitamin $\mathrm{C}$ protects liver cells from transformation into harmful lesions.

Effects of vitamin $C$ on the serum concentrations of GGT, $A L T$, and AST in DEN-induced mice. The serum concentrations of GGT, ALT, and AST were analyzed to examine hepatic function. The results showed that the serum concentrations of GGT, ALT, and AST were similar in the $\mathrm{KV}$ (vitamin C-supplemented) group compared to the WT and WV (wild-type) groups. We found no significant differences in the serum concentrations of GGT, ALT, and AST among the groups (Figure 1).

Effect of vitamin C on histopathological characteristics in DENtreated mice. In the WT group, histopathological analysis of liver tissue sections revealed severe acute cellular swelling, severe centrilobular necrosis, and some focal lymphocyte infiltrations. The WT group also showed considerable random hepatocellular degeneration as identified by cellular swelling, eosinophilic cytoplasm, and pleomorphic nuclei. In one liver section, eosinophilic intracytoplasmic inclusion bodies were observed, indicating mitochondrial damage. Contrastingly, in the KV and WV (vitamin C-supplemented) groups, such hepatic lesions were not observed. However, the WT group showed more focal lesions containing eosinophilic intracytoplasmic inclusion bodies than did the WV and KV groups. An analysis of the data suggested that vitamin $\mathrm{C}$ inhibited the induction of HCC by DEN in the KV and WV groups compared with the WT group (Figure 2). Dysplastic hepatocytes were identified as irregular and large hepatocytes with a large nucleus. The total number of binucleated hepatocytes was counted in each section. The number of binucleated hepatocytes was significantly higher in the WT group compared with that in the KV and WV groups (Figure 3). These data indicate that vitamin $\mathrm{C}$ may prevent the development of binucleated hepatocytes (22).

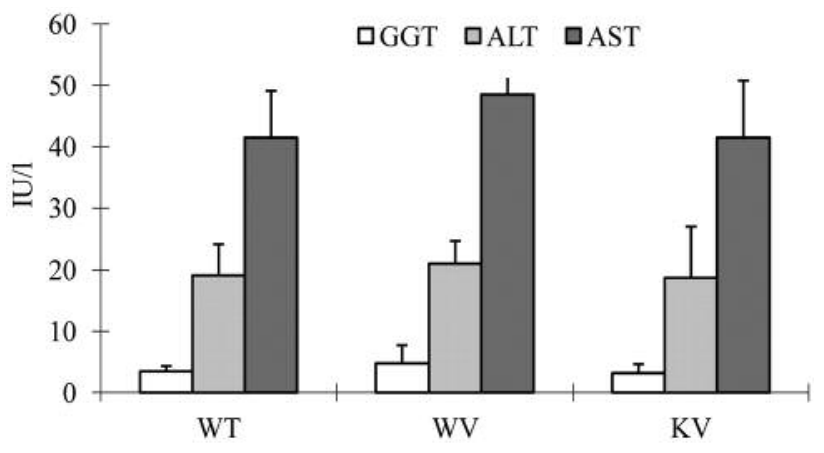

Figure 1. Biochemical analysis for liver function tests. All values are shown as mean \pm standard deviation. The serum concentrations of $\gamma$ glutamyl transpeptidase (GGT), alanine aminotransferase (ALT), and aspartate aminotransferase (AST) did not significantly differ among the experimental groups.

\section{Discussion}

$\mathrm{HCC}$ is one of the most frequently occurring malignancies worldwide and most HCC is complicated due to it occurring typically in patients with advanced hepatic disease $(5,6,23)$. $\mathrm{HCC}$ is related to various pathogenic factors such as infection with hepatitis B virus or hepatitis $\mathrm{C}$ virus, chronic hepatitis, steatosis (fatty liver), liver cirrhosis and heavy alcohol consumption $(4,24-26)$. DEN is a powerful carcinogenic agent in rodents that possibly causes its adverse effects by altering DNA structure and forming DNA adducts in the liver $(8,27)$. The DEN-induced HCC experimental model is one of the most widely used models for screening anti-hepatocarcinogenic agents due to its similarity to human HCC $(7,28)$. This animal model takes at least 8 months to develop typical HCC $(1,29)$. In this study, the final stage of HCC was not detected because the experimental period was limited to 17 weeks in consideration of the short lifespan of Smp30 KO mice (30).

The SMP30 protein is responsible for the synthesis of Lgulonic acid to L-gulono- $\gamma$-lactone, the enzyme of the last step of the vitamin C conversion pathway (31-33). Therefore, Smp30 KO mice, which are unable to synthesize vitamin $\mathrm{C}$, are used as a unique model to investigate the physiological functions of vitamin $\mathrm{C}$ in vivo (9). Vitamin $\mathrm{C}$ has various metabolic activities such as an antioxidant capacity that can protect cells from oxidative stress $(20,34)$. An antioxidative property may be defined as a capacity for the scavenging of free radicals including ROS and reactive nitrogen species by donating a hydrogen or an electron (35). There have been many reports of the therapeutic or preventive efficacy of vitamin $\mathrm{C}$ as an anticancer agent $(36,37)$, but no study of the DENinduced HCC model has been conducted using congenital vitamin C-deficient Smp30 KO mice. In the present study, we 

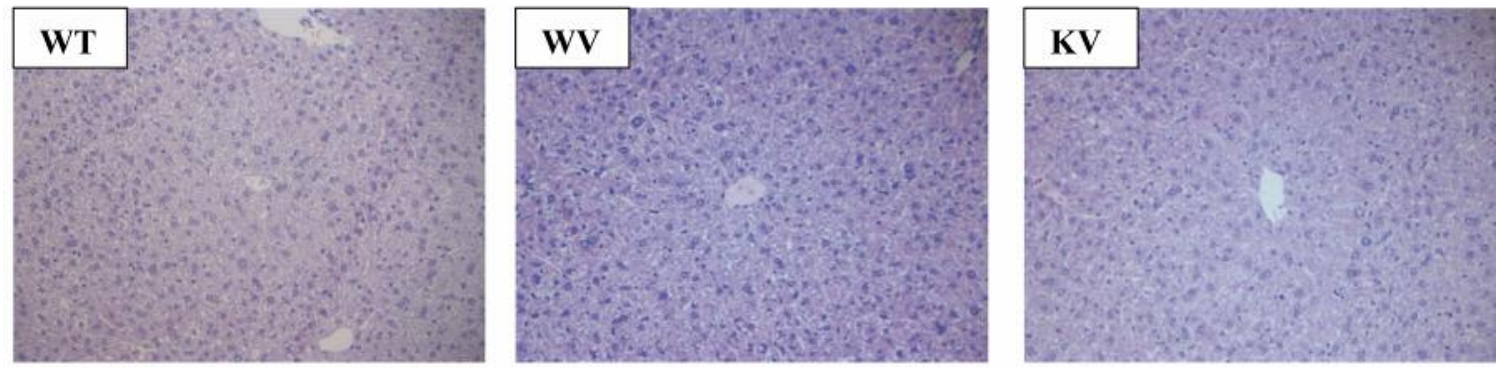

Figure 2. Microscopic and histological examination of liver tissue. The liver sections of each group were stained with hematoxylin and eosin and examined at 200x magnification. Wild-type (WT) mice fed vitamin C-free diet with tap water (WT group) showed cellular swelling, centrilobular necrosis, focal lymphocyte infiltrations, random hepatocellular degeneration, and eosinophilic intracytoplasmic inclusion bodies. In the WV group (WT mice fed vitamin C-free diet with water supplemented with $1.5 \mathrm{~g} / \mathrm{kg}$ vitamin $\mathrm{C}$ ) and $\mathrm{KV}$ group (Smp30 KO mice fed vitamin C-free diet with water supplemented of $1.5 \mathrm{~g} / \mathrm{kg}$ vitamin $C$ ) such hepatic lesions were not observed.
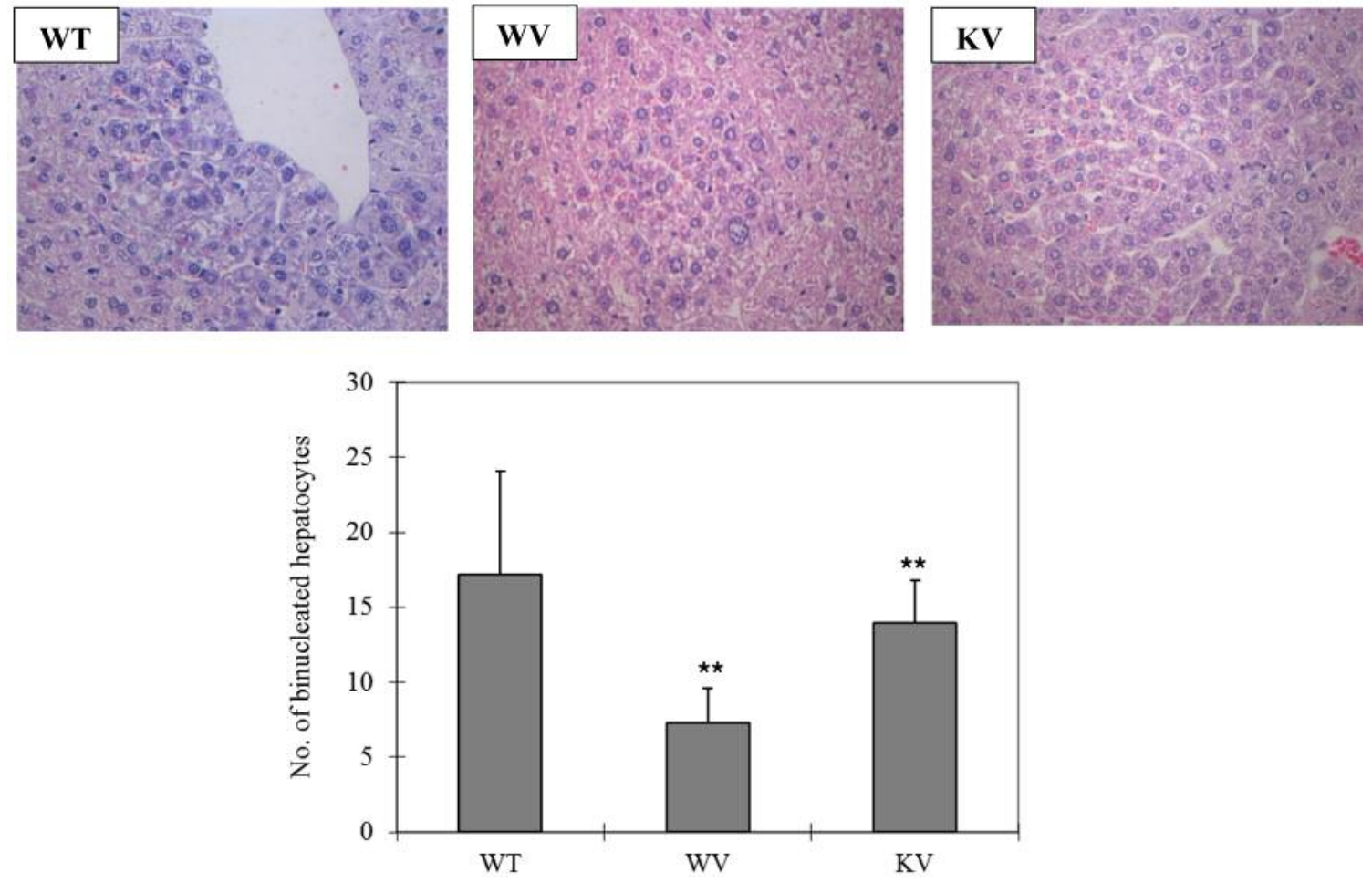

Figure 3. The numbers of binucleated hepatocytes in all groups. Liver sections were stained with hematoxylin and eosin at 400x magnification for histopathological analysis. Mice in the WT group (wild-type mice fed vitamin $C$-free diet with tap water) showed a significantly $(* * p<0.05)$ increased number of binuclear hepatocytes compared to the WV group (WT mice fed vitamin C-free diet with water supplemented of $1.5 \mathrm{~g} / \mathrm{kg}$ vitamin C) and KV group (Smp30 KO mice fed vitamin C-free diet with water supplemented of $1.5 \mathrm{~g} / \mathrm{kg}$ vitamin $\mathrm{C}$ ).

investigated the impact of vitamin C supplementation on WT and Smp30 KO mice with DEN-induced HCC.

Recently, it was shown that a hepatocyte-specific deletion of either JUN gene (c-Jun) or forkhead box protein M1 $($ Foxm $1 b)$ in mice, which both encode transcription factors needed for hepatocyte proliferation, inhibited DEN-induced hepatocarcinogenesis (38). Thus, hepatocyte proliferation is required for DEN-induced carcinogenesis. The death of DEN-exposed hepatocytes was found to activate adjacent myeloid cells (Kupffer cells) to produce hepatomitogens that 


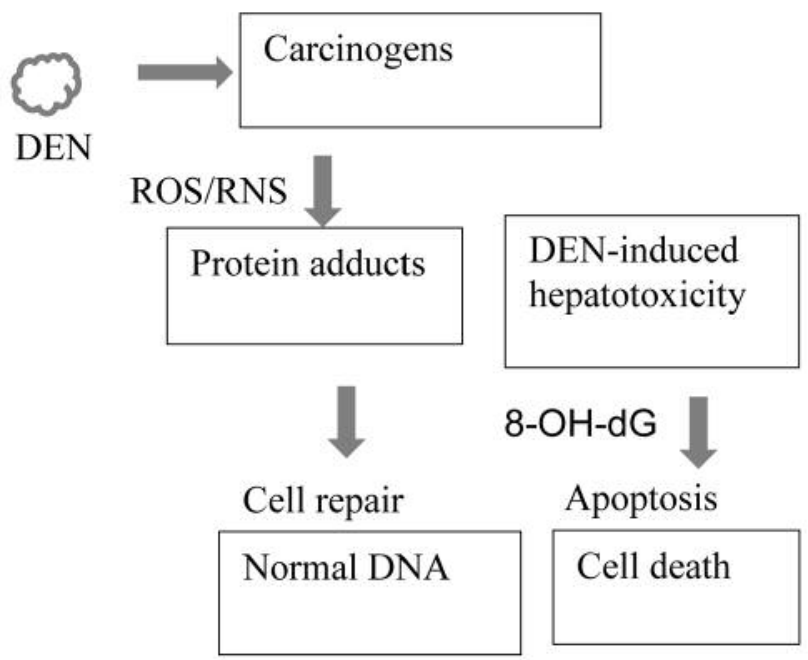

Figure 4. Schematic diagram of diethylnitrosamine (DEN)-induced hepatocellular carcinoma and intervention by vitamin C. DEN-induced hepatotoxicity was suppressed by vitamin $C$ treatment, which resulted in increased levels of phase I and phase II enzymes and decreased levels of free radicals such as reactive oxygen species $(R O S)$, reactive nitrogen species (RNS), and 8-hydroxy-2'-deoxyguanosine (8-OH-dG).

promote the proliferation of surviving hepatocytes as a compensatory effect (39).

A novel finding of this experiment is that Smp30 KO mice in the $\mathrm{KT}$ group (vitamin C-deficient) exhibited a significantly reduced lifespan compared with the KV, WT, and WV groups (Table II). These experimental data suggest that vitamin $\mathrm{C}$ is an essential compound for protection against abnormal aging $(21,40-42)$.

We assessed the serum concentrations of GGT, ALT, and AST to investigate liver function. Our data showed that there were no significant differences among the WT, WV, and KV groups. It is unclear why the serum concentrations of GGT, ALT, and AST were similar among these groups in the present study (Figure 1).

Our histopathological analyses revealed that the WT group showed increased oxidative stress induced by DEN, that caused severe acute cellular swelling (43). We also observed necrotic hepatocytes in the WT group, which were located around the central vein and had no nuclei or faint nuclei. Most lesions except centrilobular necrosis exhibited acute cellular swelling (44). The hepatocellular degeneration was more severe in the WT group than in the KV and WV (vitamin C-supplemented) groups (Figure 2). We noticed a large number of focal lesions that were round and contained eosinophilic inclusion bodies, indicating mitochondrial damage (45). Such focal lesions are composed of pleomorphic dysplastic hepatocytes and represent an early pre-neoplastic stage $(46,47)$.
In our study, significantly $(p<0.05)$ fewer binucleated hepatocytes were observed in the WV (vitamin Csupplemented wild-type) group and the KV (vitamin Csupplemented Smp30 KO) group compared with the WT group (Figure 3 ). It was reported that binucleated neuronal cells in the cortical region of the human brain in Alzheimer's disease showed severe oxidative stress (22, 48). It was demonstrated that hepatocyte binucleation is induced by an increased production of ROS, reactive nitrogen species, and other free radicals, which cause significant oxidative DNA damage in hepatic cells $(8,49$, 50). These results show that vitamin $\mathrm{C}$ might attenuate DEN-induced liver toxicity (Figure 4). All these data indicate that vitamin $\mathrm{C}$ is a promising candidate for protecting liver cells from HCC.

In conclusion, our experimental evidence suggests that vitamin C supplementation in Smp30 KO mice was effective for the treatment of DEN-induced hepatotoxicity. More detailed studies are needed to investigate the mechanisms of action of vitamin $\mathrm{C}$ in reducing DEN-induced HCC.

\section{Conflicts of interest}

The Authors declare no conflict of interest.

\section{Acknowledgements}

This work was supported by the Korea Health Technology R\&D Project through the Korea Health Industry Development Institute (KHIDI), which is funded by the Ministry of Health \&Welfare, Republic of Korea (grant number: HI15C0001).

\section{References}

1 Yamamoto M, Tanaka H, Xin B, Nishikawa Y, Yamazaki K, Shimizu K and Ogawa K: Role of the BrafV637E mutation in hepatocarcinogenesis induced by treatment with diethylnitrosamine in neonatal B6C3F1 mice. Mol Carcinog 56: 478-488, 2017.

2 Mittal S and Serag EI: Epidemiology of hepatocellular carcinoma. J Clin Gastroenterol 47: 2-6, 2013.

3 Jamal A, Bray F, Center MM, Ferlay J, Ward E and Forman D: Global cancer statistics. Cancer J Clinic 61: 69-90, 2011.

4 Baffy G: Hepatocellular carcinoma in non-alcoholic fatty liver disease: epidemiology, pathogenesis, and prevention. J Clin Translat Hepatol 1: 131-137, 2013.

5 Kanda T, Ogasawara S, Chiba T, Haga Y, Omata M and Yokosuka O: Current management of patients with hepatocellular carcinoma. World J Hepatol 7: 1913-1920, 2015.

6 Flores A and Marrero JA: Emerging trends in hepatocellular carcinoma:focus on diagnosis and therapeutics. Clin Med Insights Oncol 8: 71-76, 2014.

7 Qi Y, Chen X, Chan CY, Li D, Yuan C, Yu F, Lin MC, Yew DT, Kung HF and Lai L: Two-dimensional differential gel electrophoresis/analysis of diethylnitrosamine induced rat hepatocellular carcinoma. Int J Cancer 122: 2682-2688, 2008. 
8 Santos NP, Colaço A, da Costa RM, Oliveira MM, Peixoto F and Oliveira PA: N-Diethylnitrosamine mouse hepatotoxicity: timerelated effects on histology and oxidative stress. Exp Toxicol Pathol 66: 429-436, 2014.

9 Kondo Y, Inai Y, Sato Y, Handa S, Kubo S, Shimokado K, Goto S, Nishikimi M, Maruyama N, and Ishigami A: Senescence marker protein 30 functions as gluconolactonase in L-ascorbic acid biosynthesis, and its knockout mice are prone to scurvy. Proc Natl Acad Sci USA 103: 5723-5731, 2006.

10 Fujita T, Uchida K and Maruyama N: Purification of senescence marker protein-30 (SMP30) and its androgen-independent decrease with age in the rat liver. Biochim Biophys Acta 1116: 122-130, 1992

11 Fujita T: Senescence marker protein-30 (SMP30): Structure and biological function. Biochem Biophys Res Commun 254: 1-4, 1999.

12 Vakifahmetoglu-Norberg H, Ouchida AT and Norberg E: The role of mitochondria in metabolism and cell death. Biochem Biophys Res Commun 482: 426-431, 2017.

13 Son TG, Zou Y, Jung KJ, Yu BP, Ishigami A, Maruyama N and Lee J: SMP30 deficiency causes increased oxidative stress in brain. Mech Ageing Dev 127: 451-457, 2006.

14 Fukaya $\mathrm{Y}$ and Yamaguchi M: Regucalcin increases superoxide dismutase activity in rat liver cytosol. Biol Pharm Bull 27: 14441450, 2004.

15 Ichikawa E and Yamaguchi M: Regucalcin increases superoxide dismutase activity in the heart cytosol of normal and regucalcin transgenic rats. Int J Mol Med 14: 691-696, 2004.

16 Feng D, Kondo Y and Ishigami A: Senescence marker protein 30 as a novel antiaging molecule. Ann NY Acad Sci 1019: $360-$ 364,2004

17 Jung KJ, Ishigami A, Maruyama N, Takahashi R, Goto S, Yu BP and Chung HY: Modulation of gene expression of $S M P-30$ by LPS and calorie restriction during aging process. Exp Gerontol 39: 1169-1246, 2004

18 Birben E, Sahiner UM, Sackesen C, Erzurum S and Katayci O: Oxidative stress and antioxidant defense. World Allergy Organ J 5: 9-19, 2012

19 Maeda S, Kamata H, Luo JL, Leffert $\mathrm{H}$ and Karin M: IKK $\beta$ Couples hepatocyte death to cytokine-driven compensatory proliferation that promotes chemical hepatocarcinogenesis. Cell 121: 977-990, 2005.

20 Takahashi K, Kishimoto Y, Konishi T, Fujita Y, Ito M, Shimokado K, Maruyama $\mathrm{N}$ and Ishigami A: Ascorbic acid deficiency affects genes for oxidation-reduction and lipid metabolism in livers from Smp30/Gnl knockout mice. Biochim Biophys Acta 1840: 2289-2298, 2014

21 Conti V, Izzo V, Corbi G, Russomanno G, Manzo V, De Lise F, Di Donato A and Filippelli A: Antioxidant supplementation in the treatment of aging-associated diseases. Front Pharmacol 7: 24, 2016.

22 Park JK, Hong IH, Ki MR, Chung HY, Ishigami A, Ji AR, Goo MJ, Kim DH, Kwak JH, Min CW and Lee SS: Vitamin C deficiency increases the binucleation of hepatocytes in Smp30 knock-out mice. J Gastroenterol Hepatol 25: 1769-1776, 2010.

23 Bruix $\mathrm{J}$ and Sherman M: Management of hepatocellular carcinoma: an update. Hepatology 53: 1020-1022, 2011.

24 Makuuchi M, Kokudo N, Arii S, Futagawa S, Kaneko S, Kawasaki S, Matsuyama Y, Okazaki M, Okita K, Omata M and Saida Y: Development of evidence-based clinical guidelines for the diagnosis and treatment of hepatocellular carcinoma in Japan. Hepatol Res 38: 37-51, 2008.

25 El-Serag HB: Epidemiology of viral hepatitis and hepatocellular carcinoma. Gastroenterology 142: 1264-1273, 2012.

26 Sanyal AJ, Yoon SK and Lencioni R: The etiology of hepatocellular carcinoma and consequences for treatment. Oncologist 15: 14-22, 2010.

27 Shirakami Y, Gottesman ME and Blaner WS: Diethylnitrosamine-induced hepatocarcinogenesis is suppressed in lecithin:retinol acyltransferase-deficient mice primarily through retinoid actions immediately after carcinogen administration. Carcinogenesis 33: 268-274, 2012.

28 Yang X, Bhaumik M, Bhattacharyya R, Gong S, Rogler CE and Stanley P: New evidence for an extra-hepatic role of $\mathrm{N}$ acetylglucosaminyltransferaseIII in the progression of diethylnitrosamine-induced liver tumors I mice. Cancer Res 60: 33133321,2000

29 Lee YS, KiM WH, Yu ES, Kin MR, Lee MJ and Jang JJ: Time course of cell cycle-related protein expression in diethylnitrosamine-initiated rat liver. J Hepatol 29: 464-473, 1998.

30 Ishigami A, Kondo Y, Nanba R, Ohsawa T, Handa S, Kubo S, Akita M and Maruyama N: SMP30 deficiency in mice causes an accumulation of neutral lipids and phospholipids in the liver and shortens the life span. Biochem Biophys Res Commun 315: 575580, 2004.

31 Aizawa S, Senda M, Harada A, Maruyama N, Ishida T, Aigaki T, Ishigami A and Senda T: Structural basis of the $\gamma$-lactone-ring formation in ascorbic acid biosynthesis by the senescence marker protein-30/gluconolactonase. PloS One 8: 53706, 2013.

32 Kondo Y, Masutomi H, Noda Y, Ozawa Y, Takahashi K, Handa S, Maruyama N, Shimizu T and Ishigami A: Senescence marker protein-30/superoxide dismutase 1 double knockout mice exhibit increased oxidative stress and hepatic steatosis. FEBS open bio 4: 522-532, 2014.

33 Aumailley L, Warren A, Garand C, Dubois MJ, Paquet ER, Le Couteur DG, Marette A, Cogger VC and Lebel M: Vitamin C modulates the metabolic and cytokine profiles, alleviates hepatic endoplasmic reticulum stress, and increases the life span of

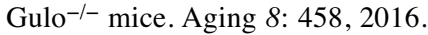

34 Kishimoto Y, Kanai T, Sato K, Lee J, Jeong KS, Shimokado K, Maruyama $\mathrm{N}$ and Ishigami $\mathrm{A}$ : Insufficient ascorbic acid intake during gestation induces abnormal cardiac dilation in fetal and neonatal SMP30/GNL knockout mice. Pediatr Res 73: 578-584, 2013.

$35 \mathrm{Kim}$, YJ, Kang KS and Yokozawa T: The anti-melanogenic effect of pycnogenol by its anti-oxidative actions. Food Chem Toxicol 46: 2466-2471, 2008.

36 Gonzalez MJ, Miranda-Massari JR, Mora EM, Guzman A, Riordan NH, Riordan HD, Casciari JJ, Jackson JA and RomanFranco A: Orthomolecular oncology reviw: ascorbic acid and cancer 25 years later. Integr Cancer Ther 4: 32-44, 2005.

37 Shekelle P, Hardy ML, Coulter I, Udani J, Spar M, Oda K, Jungvig LK, Tu W, Suttorp MJ, Valentine D, Ramirez L, Shanman R and Newberry SJ: Effect of the supplemental use of antioxidants vitamin C, vitamin E, and coenzyme Q10 for the prevention and treatment of cancer. Evid Rep Technol Assess 75: 1-3, 2003.

38 Eferl R, Ricci R, Kenner L, Zenz R, David JP, Rath M and Wagner EF: Liver tumor development. c-Jun antagonizes the proapoptotic activity of p53. Cell 112: 181-192, 2003. 
39 Pikarsky E, Porat RM, Stein I, Abramovitch R, Amit S, Kasem S, Gutkovich-Pyest E, Urieli-Shoval S, Galun E and Ben-Neriah $\mathrm{Y}$ : NF- $x \mathrm{~B}$ functions as a tumour promoter in inflammationassociated cancer. Nature 431: 461-466, 2004.

40 Pallauf K, Bendall JK, Scheiermann C, Watschinger K, Hoffmann J, Roeder T and Rimbach G: Vitamin C and lifespan in model organisms. Food Chem Toxicol 58: 255-263, 2013.

41 Sadowska-Bartosz I and Bartosz G: Effect of antioxidants supplementation on aging and longevity. BioMed Res Int 2014: 404680, 2014.

42 Harrison FE: A critical review of vitamin C for the prevention of age-related cognitivedecline and Alzheimer's disease. J Alzheimers Dis 29: 711-726, 2012.

43 Sánchez-Pérez Y, Carrasco-Legleu C, García-Cuellar C, PérezCarreón J, Hernández-García S, Salcido-Neyoy M, AlemánLazarini $\mathrm{L}$ and Villa-Treviño $\mathrm{S}$ : Oxidative stress in carcinogenesis. Correlation between lipid peroxidation and induction of preneoplastic lesions in rat hepatocarcinogenesis. Cancer Lett 217: 25-32, 2005.

44 Gujral JS, Knight TR, Farhood A, Bajt ML and Jaeschke H: Mode of cell death after acetaminophen overdose in mice: apoptosis or oncotic necrosis. Toxicol Sci 67: 322-328, 2002.

45 Thoolen B, Maronpot RR, Harada T, Nyska A, Rousseaux C, Nolte T, Malarkey DE, Kaufmann W, Küttler K, Deschl U and Nakae D: Proliferative and nonproliferative lesions of the rat and mouse hepatobiliary system. Toxicol Pathol 38: 5-81, 2010.
46 Calvisi DF and Snorri S. Thorgeirsson: Molecular mechanisms of hepatocarcinogenesis in transgenic mouse models of liver cancer. Toxicol Pathol 33: 181-184, 2005.

47 Kojiro M and Roskams T: Early hepatocellular carcinoma and dysplastic nodules. Seminars in liver disease. Vol. 25. No. 02. Copyright $^{\circledR} 2005$ by Thieme Medical Publishers, Inc., New York, NY, USA, 2005.

48 Zhu X, Siedlak SL, Wang Y, Perry G, Castellani RJ, Cohen ML and Smith MA: Neuronal binucleation in Alzheimer disease hippocampus. Neuropathol Appl Neurobiol 34: 457-465, 2008.

49 Liu CM, Zheng GH, Ming QL, Chao C and Sun JM: Sesamin protects mouse liver against nickel-induced oxidative DNA damage and apoptosis by the PI3K-Akt pathway. J Agric Food Chem 61: 1146-1154, 2013.

50 Mary VS, Arias SL, Otaiza SN, Velez PA, Rubinstein HR and Theumer MG: The aflatoxin B1-fumonisin B1 toxicity in BRL$3 \mathrm{~A}$ hepatocytes is associated to induction of cytochrome P450 activity and arachidonic acid metabolism. Environ Toxicol 32: 1711-1724, 2017.
Received September 21, 2017

Revised October 18, 2017

Accepted October 26, 2017 